\title{
In New-Onset Diabetes Mellitus, Metformin Reduces Fat Accumulation in the Liver, But Not in the Pancreas or Pericardium
}

\author{
Gábor Zsóri, MD, Dóra Illés, MD, Emese Ivány, MD, ${ }^{1}$ Klára Kosár, MD, ${ }^{1}$ \\ Gábor Holzinger, MD, ${ }^{1}$ Máté Tajti, MD, ${ }^{1}$ Eszter Pálinkás, ${ }^{1}$ Géza Szabovik, MD, ${ }^{2}$ \\ András Nagy, MD, ${ }^{2}$ András Palkó, MD, DSc, ${ }^{2}$ and László Czakó, MD, DSc ${ }^{1}$
}

\section{Abstract}

Background: Nonalcoholic fatty pancreas and liver disease (NAFPD and NAFLD) and pericardial adipose tissue (PAT) are often associated with type 2 diabetes mellitus (T2DM). Our aim was to evaluate the incidence rate of NAFLD and NAFPD, PAT size, and the effect of metformin treatment on NAFLD, NAFPD, and PAT in new-onset T2DM (NODM).

Methods: Seventeen patients with NODM and 10 subjects used as a control group were involved in the study. Computed tomography (CT) and laboratory tests were performed before the beginning of metformin therapy and 4 months afterward. PAT and the amount of fat in the pancreas and liver were determined by X-ray attenuation during unenhanced CT examination and compared with the values for the control subjects.

Results: Metabolic parameters improved significantly after metformin therapy. NAFLD was diagnosed in $64.7 \%$ of the patients with NODM and in $10 \%$ of the control subjects. The radiation absorption of the liver was significantly lower in the patients with NODM compared with the control group and significantly higher after metformin therapy compared with the baseline values. Only six patients (35.3\%) had NAFLD after metformin therapy. NAFPD was diagnosed in $82.3 \%$ of the patients with NODM and in $20 \%$ of the control subjects. The radiation absorption of the pancreas was significantly lower in the patients with NODM compared with the control group but did not change significantly after treatment. PAT size was significantly larger in the patients with NODM and did not change significantly after metformin treatment.

Conclusions: NAFLD, NAFPD, and increased PAT were detected in the majority of patients with NODM. Metformin therapy decreased the amount of fat in the liver in parallel with an improvement in the metabolic parameters and may, thus, be beneficial for preventing the late consequences of NAFLD.

AU3 Keywords: pericardial adipose tissue, type 2 diabetes mellitus, metformin, nonalcoholic fatty pancreas disease, nonalcoholic fatty liver disease

\section{Introduction}

T IS A WELL-KNOWN fact that insulin resistance, diabetes, 1 and obesity cause fat accumulation in many organs, including the liver (nonalcoholic fatty liver disease [NAFLD]), pancreas (nonalcoholic fatty pancreas disease [NAFPD]), and pericardium (pericardial adipose tissue [PAT]). ${ }^{1}$ The worldwide prevalence of NAFLD ranges widely from $6.3 \%$ to $33 \%$ with a median of $20 \%$, depending on the kind of assessment methods used. ${ }^{2-6}$ There is a high prevalence of NAFLD in patients with type 2 diabetes mellitus (T2DM) $(64 \%-$ $69 \%)^{2,7-10}$ and dyslipidemia $(20 \%-81 \%){ }^{11,12}$

Obesity, T2DM, and dyslipidemia are risk factors for the development of NAFLD. ${ }^{8,9,13,14}$ The incidence rate of prediabetes mellitus (DM) is as high as $93.3 \%$ in NAFLD, so pre-DM is a more important predictor of NAFLD than metabolic syndrome. ${ }^{15}$ Moreover, it seems that the male gender is presumably a further risk factor for NAFLD. ${ }^{2}$ If left untreated, NAFLD may progress through steatohepatitis to cirrhosis and hepatocellular carcinoma. ${ }^{16,17}$

\footnotetext{
${ }^{1}$ First Department of Medicine and ${ }^{2}$ Department of Radiology, University of Szeged, Szeged, Hungary.
} 
NAFPD is a less well-studied phenomenon. Fatty pancreas is a common ultrasound finding with increased echogenicity of the parenchyma due to fat accumulation. ${ }^{18}$ Previous studies have suggested a $16 \%-35 \%$ prevalence of fatty pancreas in the general population. ${ }^{19,20}$ It seems that age, ${ }^{21}$ obesity, hyperglycemia, and dyslipidemia are risk factors for NAFPD. ${ }^{20,22-24}$ Also, NAFPD may increase the risk for the development of metabolic syndrome by causing inflammation, ${ }^{25}$ impaired pancreatic beta cell function, and finally hyperglycemia. ${ }^{26}$ This relationship may explain the presence of $\mathrm{T}_{2} \mathrm{DM}^{27}$ in $6.9 \%-12.6 \%$ of patients with pancreatic steatosis. ${ }^{19,20}$ Several studies have suggested that insulin resistance is associated with pancreatic fat accumulation, ${ }^{22-24,28,29}$ nonalcoholic steatohepatitis (NASH), ${ }^{22,30}$ and pre-DM. ${ }^{23}$

Higher pancreatic triglyceride content in obesity can be detected by proton magnetic resonance spectroscopy, ${ }^{31}$ computed tomography (CT), ${ }^{32,33}$ or magnetic resonance imaging (MRI) ${ }^{34}$ even before the development of T2DM. ${ }^{31}$ It has been demonstrated that obesity may lead to pancreatic ductal adenocarcinoma through pancreatic steatosis. ${ }^{25,35,36}$ Evidence suggests that pancreatic steatosis plays a role in T2DM, pancreatic exocrine dysfunction, acute pancreatitis, ${ }^{37,38}$ pancreatic cancer, and the formation of pancreatic fistulas after pancreatic surgery. ${ }^{39}$

NAFLD and NAFPD are associated with each other because pancreatic fat formation is related to NASH and is a significant predictor of the presence of NAFLD. ${ }^{40}$ The elevation of liver transaminases may suggest the presence of NAFLD or NASH. Ultrasonography and transient elastography are currently the most appropriate imaging modality for NAFLD screening, and liver biopsy is the "gold standard" for characterizing liver histology in patients with NAFLD. ${ }^{41}$ In contrast to the liver, no biochemical marker is available for diagnosing NAFPD. Further, as the pancreas is a retroperitoneal organ, a pancreatic biopsy is more cumbersome and may be accompanied by more sampling errors and complications compared with a liver biopsy. Visualizing the pancreas by ultrasonography is more difficult, and the sensitivity and specificity of ultrasonography in detecting NAFPD are hampered by obesity and bloating.

Further, in prediabetic and T2DM patients, the amount of PAT is significantly higher compared with that in normoglycemic patients. ${ }^{42,43}$ Previous reviews have demonstrated that, besides epicardial adipose tissue, PAT is another risk factor for the development of cardiovascular disease in T2DM patients. ${ }^{44}$

The aim of this study was to evaluate the incidence rate of NAFLD and NAFPD, PAT size, and the effect of metformin treatment on NAFLD, NAFPD, and PAT in new-onset T2DM (NODM) by measuring tissue attenuation during unenhanced $\mathrm{CT}$ examination.

\section{Subjects and Methods}

Seventeen patients with NODM (male: 8; female: 9; mean age: $55.3 \pm 10.8$ years; body mass index [BMI]: $31.8 \pm$ $5.1 \mathrm{~kg} / \mathrm{m}^{2}$ ) were involved in this prospective study. The control group comprised 10 healthy subjects (male: 6; female: 4 ; mean age: $53.9 \pm 13.8$ years; BMI: $30.0 \pm 4.7 \mathrm{~kg} / \mathrm{m}^{2}$ ) without DM, without the presence of any pancreatic, liver, or cardiovascular disease, or history of alcohol consumption

T1 and matched for age, sex, BMI, and serum lipids (Table 1).

The diagnosis of T2DM was made in accordance with the American Diabetes Association criteria. ${ }^{45}$ NODM is defined
Table 1. Age, Body Mass Index, Cholesterol, AND TRIGlyCeride LEVEls IN PATIENTS with New-Onset Type 2 Diabetes Mellitus and Healthy Control Subjects at Baseline

\begin{tabular}{lccc}
\hline & $\begin{array}{c}\text { Control } \\
\text { (male: } \\
\text { female: }\end{array}$ & $\begin{array}{c}\text { NODM } \\
\text { (male: } 8 ;\end{array}$ & \\
female: 9$)$ & $\mathrm{P}$ \\
\hline Age (years) & $53.9 \pm 13.8$ & $55.3 \pm 10.8$ & 0.521 \\
BMI (kg/m $\left.{ }^{2}\right)$ & $30.0 \pm 4.7$ & $31.8 \pm 5.1$ & 0.437 \\
$\begin{array}{l}\text { Serum cholesterol } \\
(\mathrm{mM})\end{array}$ & $5.1 \pm 0.9$ & $5.7 \pm 1.9$ & 0.187 \\
$\begin{array}{c}\text { Serum triglyceride } \\
(\mathrm{mg} / \mathrm{dL})\end{array}$ & $3.3 \pm 2.7$ & $3.1 \pm 1.8$ & 0.830 \\
& & & \\
\hline
\end{tabular}

Data expressed as mean values \pm SD.

BMI, body mass index; NODM, new-onset type 2 diabetes mellitus; SD, standard deviation.

as DM diagnosed within the past 1 month before the date of enrollment. Patients were only on a low-carbohydrate diet and received no hypoglycemic agents before inclusion. Exclusion criteria consisted of any pancreatic, liver, or cardiovascular disease, inherited disorders of fat metabolism, pregnancy, malignant disease, antidiabetic medication, or alcohol consumption in patients' medical records. NODM patients received no other new drugs beyond $1000 \mathrm{mg}$ metformin twice daily after inclusion. However, a hypolipidic diet was recommended to patients with elevated lipid levels. The follow-up period was 4 months. CT and laboratory tests (serum triglyceride, cholesterol, insulin level, fasting blood glucose, and glycosylated hemoglobin [HbA1c]) were performed before the beginning of metformin therapy and 4 months afterward. Homeostatic model assessment-estimated insulin resistance (HOMA-IR) was also calculated. PAT size and the amount of fat in the pancreas and liver were determined by $\mathrm{X}$-ray attenuation rate during unenhanced $\mathrm{CT}$ examination (Hounsfield unit [HU]) (Fig. 1). Each region of interest (ROI) in the liver, $4 \mathrm{~F} 1$ pancreas, and spleen was a round area of $\sim 1.0 \mathrm{~cm}^{2}$ as a marker of the degree of attenuation. ${ }^{46}$ In the case of PAT, measurements were performed in one dedicated slice at the junction of the inferior vena cava and right atrium. ROIs were identified in Segment VII of the liver, along the diaphragmatic surface of the spleen and in the body of the pancreas. Mean density was calculated, and General Electric Centricity PACS software was used to determine the values. NAFLD and NAFPD were defined when the liver-to-spleen or pancreas-to-spleen attenuation ratio was $<1 .{ }^{47,48}$

All the participants provided written informed consent. The study protocol was in full accordance with the most recent revisions of the Helsinki Declaration and was approved by the ethics committee at the University of Szeged.

\section{Statistical analysis}

Continuous measures are summarized and presented as means and standard deviations. Categorical data are presented as percentages. The two-sample $t$-test and pairedsamples $t$-test were used to determine differences between continuous parameters. Non-normally distributed data were $\log$ transformed. Data were processed with SPSS 22.0 (Armonk, NY), and a level of $P<0.05$ was considered statistically significant. 

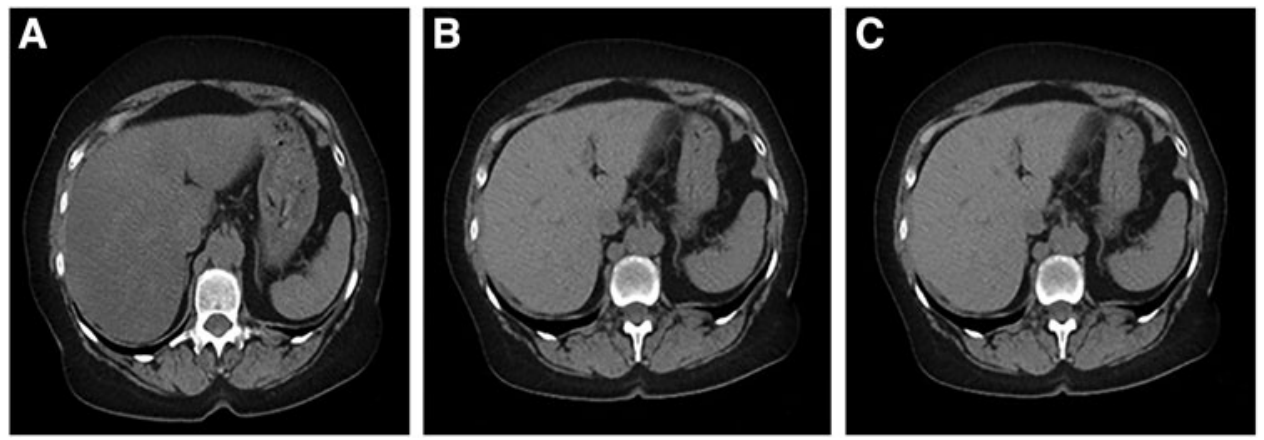

FIG. 1. Typical plain CT images in new-onset type 2 diabetic patients before and 4 months after the start of metformin therapy and in control subjects. The density of the liver was diffusely decreased in new-onset type 2 diabetic patients (A) as compared with control (C). Metformin therapy increased liver density in the diabetic patients (B) like the density in the control liver (C). CT, computed tomography.

\section{Results}

Fasting blood glucose, HbA1c, serum insulin and cholesterol, and HOMA-IR decreased significantly after met-

T2 formin therapy compared with the baseline values (Table 2). However, serum triglyceride and BMI did not change.

NAFLD was diagnosed in $64.7 \%$ (11 out of 17) of the patients with NODM and in 10\% of the control subjects based on the diagnostic criteria. NODM patients with and

T3 without NAFLD were compared (Table 3). The amount of fat in the liver was significantly higher in NODM patients with NAFLD than in those without it $(25.2 \pm 12.7$ vs. $55.6 \pm 9.3 \mathrm{HU})$. The serum cholesterol level was significantly higher in patients without NAFLD as compared with patients with the disease in the NODM group $(P=0.002)$. BMI, serum triglyceride, fasting blood glucose level, HbA1c, and liver enzymes were not significantly different between patients with and without NAFLD (Table 3 ).

The radiation absorption of the liver was significantly lower in patients with NODM compared with the control group $(32.3 \pm 17.7$ vs. $53.1 \pm 8.3 \mathrm{HU}[P=0.001])$ and significantly increased after metformin therapy compared with

Table 2. Changes of Laboratory Test Results and Body Mass Index from Baseline Values to 4 Months Afterward During Metformin Therapy in Patients with New-Onset Type 2 DiABETES MELLITUS

\begin{tabular}{|c|c|c|c|c|}
\hline & & $\begin{array}{c}\text { Baseline } \\
\text { values } \\
\text { (male: } 8 ; \\
\text { female: } 9 \text { ) }\end{array}$ & $\begin{array}{l}4 \text { months } \\
\text { afterward } \\
\text { (male: } 8 ; \\
\text { female: } 9 \text { ) }\end{array}$ & $\mathrm{P}$ \\
\hline \multirow[t]{7}{*}{ AU6 } & $\begin{array}{l}\text { Fasting blood glucose } \\
(\mathrm{mM})\end{array}$ & $12.9 \pm 4.8$ & $7.0 \pm 1.4$ & 0.001 \\
\hline & $\operatorname{HbA} 1 \mathrm{c}(\%)$ & $9.6 \pm 2.8$ & $6.7 \pm 0.8$ & $<0.001$ \\
\hline & Serum insulin (mU/L) & $33.1 \pm 18.3$ & $22.2 \pm 11.5$ & 0.003 \\
\hline & HOMA-IR (molar units) & $16.6 \pm 9.0$ & $7.1 \pm 3.1$ & $<0.001$ \\
\hline & Serum cholesterol (mM) & $4.8 \pm 1.0$ & $4.4 \pm 1.0$ & 0.016 \\
\hline & $\begin{array}{l}\text { Serum triglyceride } \\
(\mathrm{mg} / \mathrm{dL})\end{array}$ & $2.9 \pm 1.1$ & $2.4 \pm 1.3$ & 0.299 \\
\hline & BMI $\left(\mathrm{kg} / \mathrm{m}^{2}\right)$ & $31.8 \pm 5.1$ & $31.6 \pm 4.4$ & 0.757 \\
\hline
\end{tabular}

Data expressed as mean values $\pm \mathrm{SD}$.

HbA1c, glycosylated hemoglobin; HOMA-IR, homeostatic model assessment-estimated insulin resistance, the baseline values ( $32.3 \pm 17.7$ vs. $47.3 \pm 12.1 \mathrm{HU}[P=0.026])$ (Fig. 2). Only six patients (35.3\%) had NAFLD after the $4 \mathrm{~F} 2$ 4-month metformin therapy according to the diagnostic criteria.

NAFPD was diagnosed in $82.3 \%$ (14 out of 17 ) of the patients with NODM and in $20 \%$ of the control subjects based on the diagnostic criteria. The amount of fat in the pancreas was significantly higher in the NODM patients with NAFPD than in those without it $(30.2 \pm 6.9$ vs. $45.4 \pm 3.9 \mathrm{HU}[P<0.001])$. The radiation absorption of the pancreas was significantly lower in the patients with NODM compared with the control group $(34.0 \pm 7.9$ vs. $39.4 \pm 7.8$ HU $[P=0.04])$ but did not change significantly after the 4-month metformin treatment $(34.0 \pm 7.9$ vs. $37.7 \pm 10.2 \mathrm{HU}$ $[P=0.178]$ ) (Fig. 3).

PAT size was significantly larger in the patients with NODM compared with the control group $(2143.1 \pm 1036$ vs. $\left.1223.9 \pm 312.9 \mathrm{~mm}^{2}[P=0.008]\right)$ and did not change significantly after the metformin treatment $(2143.1 \pm 1036$ vs. $2048.2 \pm 997 \mathrm{~mm}^{2}[P=0.798]$ ) (Fig. 4).

\section{Discussion and Conclusions}

This study demonstrates that NAFLD and NAFPD are already present and PAT volume is increased in patients with NODM. Metformin therapy effectively decreased the amount of fat in the liver but did not affect the amount of fat in the pancreas or PAT volume.

NAFLD is the most common liver disorder worldwide and contributes significantly to overall mortality and to cardiovascular and liver-related mortality in particular. The main risk factor is T2DM; NAFLD can be demonstrated in $64 \%-69 \%$ of T2DM patients. ${ }^{2,7-9}$ It is likely that NAFLD is the hepatic manifestation of metabolic syndrome, where insulin resistance is the main risk factor. ${ }^{49}$ On the other hand, NAFLD may progress to an inflammatory complication, NASH. The high incidence of NASH in patients with T2DM may lead to further complications, such as liver cirrhosis and hepatocellular carcinoma. ${ }^{16,17}$ Given the expected rise in the prevalence of T2DM, NAFLD is projected to be the principal etiology for liver transplantation within the next decade. ${ }^{7}$ Further, NAFLD is believed to be an independent determinant of cardiovascular disease..$^{50}$

Metabolic syndrome and obesity are commonly associated with NAFLD. However, the links between NAFLD, 
Table 3. Amount of Fat in the Liver, Cholesterol, Triglyceride, Body Mass Index, Fasting Blood Glucose, Hba1c, and Liver Enzyme Values in New-Onset Type 2 Diabetes Mellitus Patients With and Without Nonalcoholic Fatty Liver Disease at Baseline

\begin{tabular}{|c|c|c|c|}
\hline & $\begin{array}{l}\text { Patients with NAFLD } \\
\text { (male: 6; female: } 5 \text { ) }\end{array}$ & $\begin{array}{l}\text { Patients without NAFLD } \\
\text { (male: } 2 ; \text { female: } 4)\end{array}$ & $\mathrm{P}$ \\
\hline The amount of fat in the liver (HU) & $25.2 \pm 12.7$ & $55.6 \pm 9.3$ & 0.002 \\
\hline Serum cholesterol $(\mathrm{mM})$ & $5.5 \pm 1.1$ & $5.8 \pm 0.3$ & 0.002 \\
\hline Serum triglyceride (mg/dL) & $2.7 \pm 1.4$ & $2.9 \pm 1.5$ & 0.776 \\
\hline BMI $\left(\mathrm{kg} / \mathrm{m}^{2}\right)$ & $31.6 \pm 5.2$ & $29.2 \pm 5.6$ & 0.233 \\
\hline Aspartate aminotransferase (U/L) & $20.6 \pm 5.5$ & $16.5 \pm 3.0$ & 0.123 \\
\hline Alanine aminotransferase (U/L) & $24.9 \pm 8.6$ & $19.5 \pm 6.5$ & 0.151 \\
\hline Alkaline phosphatase (U/L) & $76.8 \pm 18.0$ & $83.5 \pm 24.4$ & 0.717 \\
\hline Gamma glutamyltransferase (U/L) & $43.9 \pm 15.2$ & $46.3 \pm 25.6$ & 0.901 \\
\hline Total bilirubin $(\mu \mathrm{M})$ & $8.1 \pm 1.7$ & $5.9 \pm 2.5$ & 0.245 \\
\hline Fasting blood glucose (mM) & $13.9 \pm 5.9$ & $12.3 \pm 9.2$ & 0.882 \\
\hline $\mathrm{HbA1c}(\%)$ & $9.4 \pm 2.1$ & $9.2 \pm 2.8$ & 0.924 \\
\hline HOMA-IR & $17.8 \pm 8.3$ & $11.4 \pm 9.5$ & 0.368 \\
\hline
\end{tabular}

Data expressed as mean value $\pm \mathrm{SD}$.

HU, Hounsfield unit; NAFLD, nonalcoholic fatty liver disease.

insulin resistance, and T2DM are not fully understood. ${ }^{7}$ NAFLD can predict the incidence of diabetes independently of traditional risk factors, including obesity, peripheral insulin resistance, and metabolic syndrome. ${ }^{51}$ Moreover, diabetes promotes or worsens hepatic steatosis, thus fueling a vicious cycle.

PAT plays a role in myocardial energy metabolism through the connection with the coronary arteries and the myocardium. ${ }^{52,53}$ Increased pericardial fat volume was demonstrated as a risk factor for coronary artery disease ${ }^{54}$ and the development of cardiovascular disease in T2DM patients. ${ }^{44}$ In the Jackson heart study, PAT was associated with elevated levels of fasting glucose, triglycerides, C-reactive protein, systolic blood pressure, and lower levels of high-density lipoprotein. ${ }^{53}$ Moreover, PAT was also linked to metabolic syndrome, hypertension, T2DM, and metabolic syndrome. ${ }^{53}$ Further, Lozzo found increased PAT volume in T2DM patients. ${ }^{43}$ We demonstrated that PAT volume is already higher in NODM; however, metformin therapy did not af-

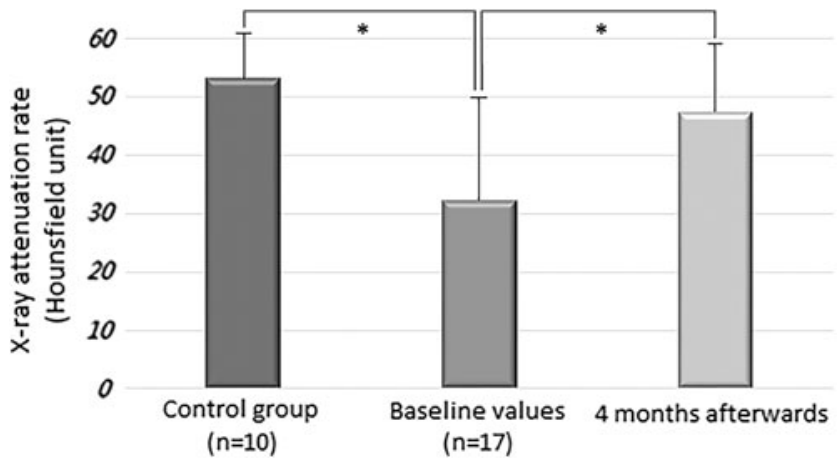

FIG. 2. The radiation absorption of the liver in new-onset type 2 diabetic patients before and 4 months after the start of metformin therapy and in control subjects. The X-ray attenuation rate during a native $\mathrm{CT}$ examination was measured in new-onset type 2 diabetic patients before and 4 months after the start of metformin therapy and in control subjects. Data expressed as mean values $\pm \mathrm{SD}$. $* P<0.05$. SD, standard deviation. fect PAT volume. The latter finding is in line with a previous study, where 24 -week-long metformin treatment did not change PAT size. ${ }^{55}$ The mechanisms of metformin are complex and are still not fully understood. Metformin works directly or indirectly on the liver to reduce hepatic glucose production, affects the gut to increase glucose utilization and the level of glucagon-like peptide-1 (GLP-1), and alters the microbiome. ${ }^{56}$ The GLP-1 receptor is also expressed in the adipose tissue, and GLP-1 promotes adipogenesis by upregulation of adipocyte-specific markers and transcription factors. ${ }^{57}$ This may explain why metformin did not decrease PAT volume, although it had a beneficial effect on metabolic parameters.

In our study, a T2DM patient cohort was selected to analyze the effect of insulin resistance on the prevalence of NAFLD. The control subjects did not have DM or any pancreatic, liver, or cardiovascular disease, or history of alcohol consumption, but they were matched for age, sex, BMI, and serum lipids. Therefore, NODM was the only variable in our study that could influence the prevalence of

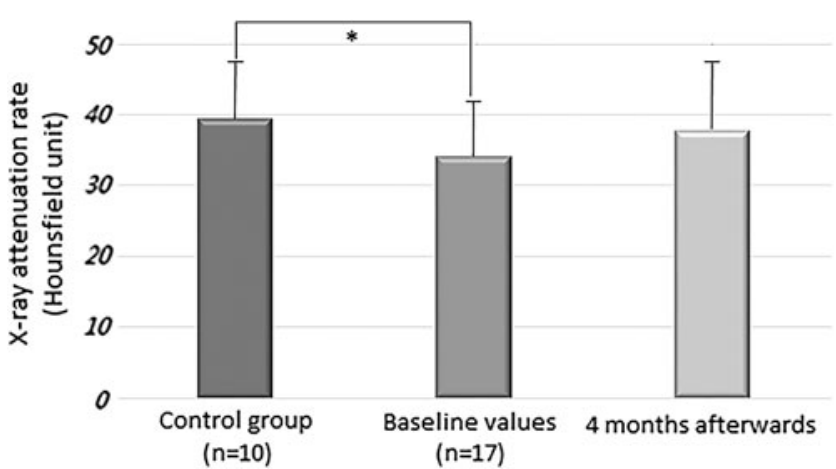

FIG. 3. The radiation absorption of the pancreas in newonset type 2 diabetic patients before and 4 months after the start of metformin therapy and in control subjects. The Xray attenuation rate during a native $\mathrm{CT}$ examination was measured in new-onset type 2 diabetic patients before and 4 months after the start of metformin therapy and in control subjects. Data expressed as mean values \pm SD. ${ }^{*} P<0.05$. 


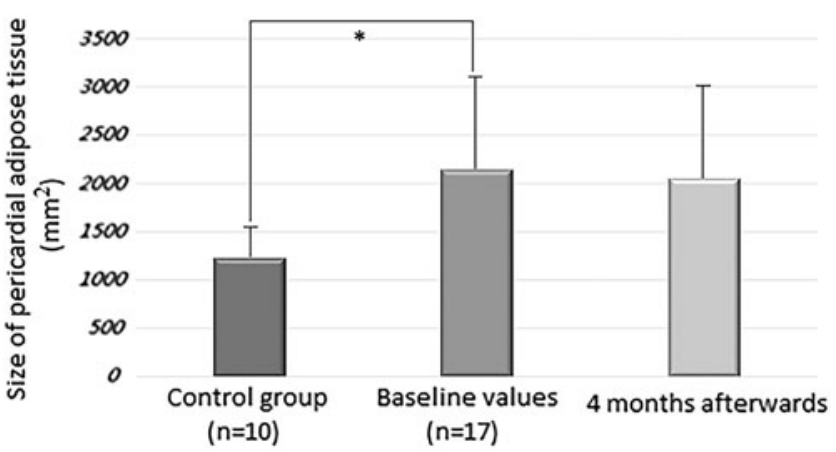

FIG. 4. The size of pericardial adipose tissue in new-onset type 2 diabetic patients before and 4 months after the start of metformin therapy and in control subjects. A native CT examination was measured in new-onset type 2 diabetic patients before and 4 months after the start of metformin therapy and in control subjects. Data expressed as mean values \pm SD. $* P<0.05$.

NAFLD. Patients with NODM were enrolled in this prospective study if they had been diagnosed within 1 month, they consumed no alcohol, and their medical records showed no pancreatic, liver, or cardiovascular disease, inherited disorders of fat metabolism, antidiabetic medication or pregnancy, or malignant disease. The aims of the study were (1) to analyze the effect of early phase insulin resistance on the development of NAFLD and NAFPD and (2) to investigate the effect of newly introduced metformin therapy on the degree of fat content in the liver and pancreas and on PAT size.

Sixty-nine percent and $62 \%$ of T2DM patients had NAFLD as defined by ultrasound in two previous studies, 8,9 and $87 \%$ of the NAFLD cases were confirmed histologically in the latter study. However, these studies featured a crosssectional design that included diabetic patients with variable disease lengths. We involved NODM patients diagnosed within 1 month before enrollment in our study. Overall, $64.7 \%$ of newly diagnosed diabetic patients in our investigation had NAFLD. This means that NAFLD is already present in the early phase of DM. The high prevalence of NAFLD in our study can be explained by the fact that our patients had several risk factors. They were generally overweight and had elevated cholesterol and triglyceride levels. However, BMI, serum cholesterol, and triglyceride levels were also above normal in the control group, and there were no significant differences between the control group and the DM group. In contrast, only $10 \%$ of the control subjects had NAFLD. Further, the radiation absorption of the liver was significantly lower, indicating a higher amount of fat in the liver in patients with T2DM compared with the control group. This increased amount of fat, therefore, can be attributed to insulin resistance after excluding other risk factors. It was demonstrated that insulin resistance is already present at least 5 years before overt diabetes in populations with a high prevalence of T2DM. ${ }^{58}$ The high prevalence of NAFLD can also be explained by the fact that we defined fatty liver by measuring radiation absorption on CT, which is more sensitive, specific, and operator-independent compared with ultrasound.

NAFPD has been poorly investigated compared with NAFLD, although interest is increasing among researchers. Reports on the relationship between NAFPD and $\beta$-cell function are inconsistent. Some studies indicate that pancreatic lipid content is negatively associated with insulin secretion in nondiabetic subjects ${ }^{27}$ or individuals with prediabetes ${ }^{26}$ whereas others suggest that there is no relationship between $\beta$ cell function and pancreatic fat in prediabetic ${ }^{59}$ or diabetic subjects. $^{27}$

Pancreatic fat content can be studied with multiple diagnostic modalities. A histological examination requires a pancreatic biopsy. However, this is invasive, and there are complications associated with it. Ultrasonography is cheap and easily available, but a relatively insensitive measure of pancreatic fat content. More recently, expensive MRI techniques have been used to assess pancreatic fat deposition. A native CT scan was employed in our study to measure the amount of pancreatic steatosis using radiation absorption correlated to the spleen.

Diabetic patients have been demonstrated to have higher pancreatic fat content as measured by magnetic resonance spectroscopy ${ }^{27,31}$ and dual-echo magnetic resonance chemical shift imaging. ${ }^{60}$ In contrast, Saisho et al. found that pancreatic fat content was not significantly increased in T2DM. ${ }^{61}$ Overall, $82.3 \%$ of NODM patients were diagnosed as having NAFPD based on the diagnostic criteria, whereas NAFPD was only detected in $20 \%$ of the control population in our study. Since the control group was matched for age, sex, BMI, and serum lipids with the T2DM group, NAFPD may be a consequence of insulin resistance.

Newly ( $<1$ month) diagnosed T2DM patients were enrolled in the study to assess the effect of metformin on NAFLD and NAFPD. Metformin is the first-line agent for the treatment of diabetes and the most popular antidiabetic agent worldwide. The effects of metformin on NAFLD have been evaluated in several studies, with some of them showing a beneficial effect on aminotransferase levels or liver histological alterations. ${ }^{2,62-64}$ To our knowledge, no study has ever evaluated the effect of metformin on hepatic fat content measured by tissue attenuation during unenhanced CT examination. Four-month-long metformin treatment significantly reduced fat content in the liver in our study. Metformin also improved glycemic control and insulin resistance, as measured by HOMA-IR, and lowered serum cholesterol level, the results of which can partly be attributed to its beneficial effects. However, metformin therapy did not reduce pancreatic fat content and PAT size.

In conclusion, NAFLD, NAFPD, and increased PAT were detected in the majority of the NODM patients. Metformin therapy lowered the amount of fat in the liver in parallel with the improvement in metabolic parameters but did not decrease the level of adipose tissue in the pancreas nor reduce PAT size. Metformin therapy started early in the course of diabetes may be beneficial for the prevention of the late consequences of NAFLD.

\section{Acknowledgments}

The study was partly funded by a grant (K 128222 to L.C.) from the Hungarian National Research, Development and Innovation Office.

\section{Author Disclosure Statement}

The article has been read, understood, and approved by all the authors. The authors declare that this article is not under 
review elsewhere and that it has not been published earlier. They have no commercial associations that might represent a conflict of interest in relation to the submitted article.

\section{AU4 References}

1. Eguchi Y, Eguchi T, Mizuta T, et al. Visceral fat accumulation and insulin resistance are important factors in nonalcoholic fatty liver disease. J Gastroenterol 2006;41: 462-469.

2. Vernon G, Baranova A, Younossi ZM. Systematic review: The epidemiology and natural history of non-alcoholic fatty liver disease and non-alcoholic steatohepatitis in adults. Aliment Pharmacol Ther 2011;34:274-285.

3. Williams CD, Stenger J, Asike MI, et al. Prevalence of nonalcoholic fatty liver disease and nonalcoholic steatohepatitis among a largely middle-aged population utilizing ultrasound and liver biopsy: A prospective study. Gastroenterology 2011;140:124-131.

4. Browning JD, Szczepaniak LS, Dobbins R, et al. Prevalence of hepatic steatosis in an urban population in the United States: Impact of ethnicity. Hepatology 2004;40: 1387-1395.

5. Williamson RM, Price JF, Glancy S, et al. Prevalence of and risk factors for hepatic steatosis and nonalcoholic Fatty liver disease in people with type 2 diabetes: The Edinburgh Type 2 Diabetes Study. Diabetes Care 2011;34:1139-1144.

6. Bedogni G, Miglioli L, Masutti F, et al. Prevalence of and risk factors for nonalcoholic fatty liver disease: The Dionysos nutrition and liver study. Hepatology 2005;42:44-52.

7. Richard J, Lingvay I. Hepatic steatosis and type 2 diabetes: Current and future treatment considerations. Expert Rev Cardiovasc Ther 2011;9:321-328.

8. Leite NC, Salles GF, Araujo AL, et al. Prevalence and associated factors of non-alcoholic fatty liver disease in patients with type-2 diabetes mellitus. Liver Int 2009;29: 113-119.

9. Prashanth M, Ganesh HK, Vima MV, et al. Prevalence of nonalcoholic fatty liver disease in patients with type $2 \mathrm{di}$ abetes mellitus. J Assoc Physicians India 2009;57:205-210.

10. Bellentani S. The epidemiology of non-alcoholic fatty liver disease. Liver Int 2017;37:81-84.

11. Gaggini M, Morelli M, Buzzigoli E, et al. Non-alcoholic fatty liver disease (NAFLD) and its connection with insulin resistance, dyslipidemia, atherosclerosis and coronary heart disease. Nutrients 2013;5:1544-1560.

12. Assy N, Kaita K, Mymin D, et al. Fatty infiltration of liver in hyperlipidemic patients. Dig Dis Sci 2000;45:1929-1934.

13. Naga C, Zobair Y, Joel EL, et al. The diagnosis and management of non-alcoholic fatty liver disease: Practice Guideline by the American Association for the Study of Liver Diseases, American College of Gastroenterology, and the American Gastroenterological Association. Hepatology 2012;55:2005-2023.

14. Musso G, Gambino R, Cassader M, et al. Meta-analysis Natural history of non-alcoholic fatty liver disease (NAFLD) and diagnostic accuracy of non-invasive tests for liver disease severity. Ann Med 2011;43:617-649.

15. Zelber-Sagi S, Lotan R, Shibolet O, et al. Non-alcoholic fatty liver disease independently predicts prediabetes during a 7-year prospective follow-up. Liver Int 2013;33: 1406-1412.

16. Sanyal AJ, Banas C, Sargeant C, et al. Similarities and differences in outcomes of cirrhosis due to nonalcoholic steatohepatitis and hepatitis C. Hepatology 2006;42:132-138.
17. Adams LA, Lymp JF, Sauver JST, et al. The natural history of nonalcoholic fatty liver disease: A population-based cohort study. Gastroenterology 2005;129:113-121.

18. Li S, Su L, Lv G, et al. Transabdominal ultrasonography of the pancreas is superior to that of the liver for detection of ectopic fat deposits resulting from metabolic syndrome. Medicine (Baltimore) 2017;96:8060.

19. Wang CY, Ou HY, Chen MF, et al. Enigmatic ectopic fat: Prevalence of nonalcoholic fatty pancreas disease and its associated factors in a Chinese population. J Am Heart Assoc 2014;3:000297.

20. Lesmana CRA, Pakasi LS, Inggriani S, et al. Prevalence of non-alcoholic fatty pancreas disease (NAFPD) and its risk factors among adult medical check-up patients in a private hospital: A large cross sectional study. BMC Gastroenterol 2015; 15:174.

21. Li J, Xie Y, Yuan F, et al. Noninvasive quantification of pancreatic fat in healthy male population using chemical shift magnetic resonance imaging: Effect of aging on pancreatic fat content. Pancreas 2011;40:295-299.

22. Wu W-C, Wang C-Y. Association between non-alcoholic fatty pancreatic disease (NAFPD) and the metabolic syndrome: Case-control retrospective study. Cardiovasc Diabetol 2013;12:77.

23. Ou H-Y, Wang C-Y, Yang Y-C, et al. The association between nonalcoholic fatty pancreas disease and diabetes. PLoS One 2013;8:62561.

24. Sepe PS, Ohri A, Sanaka S, et al. A prospective evaluation of fatty pancreas by using EUS. Gastrointest Endosc 2011; 73:987-993.

25. Pitt HA. Hepato-pancreato-biliary fat: The good, the bad and the ugly. HPB (Oxford) 2007;9:92-97.

26. Heni M, Machann J, Staiger $\mathrm{H}$, et al. Pancreatic fat is negatively associated with insulin secretion in individuals with impaired fasting glucose and/or impaired glucose tolerance: A nuclear magnetic resonance study. Diabetes Metab Res Rev 2010;26:200-205.

27. Tushuizen ME, Bunck MC, Pouwels PJ, et al. Pancreatic fat content and beta-cell function in men with and without type 2 diabetes. Diabetes Care 2007;30:2916-2921.

28. Pacifico L, Di Martino M, Anania C, et al. Pancreatic fat and $\beta$-cell function in overweight/obese children with nonalcoholic fatty liver disease. World $J$ Gastroenterol 2015;21:4688-4695.

29. Targher G, Rossi AP, Zamboni GA, et al. Pancreatic fat accumulation and its relationship with liver fat content and other fat depots in obese individuals. $J$ Endocrinol Invest 2012;35:748-753.

30. Musso G, Cassader M, De Michieli F, et al. Nonalcoholic steatohepatitis versus steatosis: Adipose tissue insulin resistance and dysfunctional response to fat ingestion predict liver injury and altered glucose and lipoproteinmetabolism. Hepatology 2012;56:933-942.

31. Lingvay I, Esser V, Legendre JL, et al. Noninvasive quantification of pancreatic fat in humans. J Clin Endocrinol Metab 2009;94:4070-4076.

32. Yu TY, Wang CY. Impact of non-alcoholic fatty pancreas disease on glucose metabolism. J Diabetes Investig 2017;8: 735-747.

33. Katz DS, Hines J, Math KR, et al. Using CT to reveal fatcontaining abnormalities of the pancreas. AJR Am J Roentgenol 1999;172:393-396.

34. Kovanlikaya A, Mittelman SD, Ward A, et al. Obesity and fat quantification in lean tissues using three-point Dixon MR imaging. Pediatr Radiol 2005;35:601-607. 
35. Bracci PM. Obesity and pancreatic cancer: Overview of epidemiologic evidence and biologic mechanisms. Mol Carcinog 2012;51:53-63.

36. Hori M, Takahashi M, Hiraoka N, et al. Association of pancreatic fatty infiltration with pancreatic ductal adenocarcinoma. Clin Translat Gastroenterol 2014;13:53.

37. Papachristou GI, Papachristou DJ, Avula H, et al. Obesity increases the severity of acute pancreatitis: Performance of APACHE-O score and correlation with the inflammatory response. Pancreatology 2006;6:279-285.

38. Martinez J, Johnson CD, Sanchez-Paya J, et al. Obesity is a definitive risk factor of severity and mortality in acute pancreatitis: An updated meta-analysis. Pancreatology 2006;6:206-209.

39. Pietro A, Addeo JRD, Francois P, et al. Pancreatic fistula after a pancreaticoduodenectomy for ductal adenocarcinoma and its association with morbidity: A multicentre study of the French Surgical Association. HPB (Oxford) 2014;16:46-55.

40. Van Geenen EJ, Smits MM, Schreuder TC, et al. Nonalcoholic fatty liver disease is related to nonalcoholic fatty pancreas disease. Pancreas 2010;39:1185-1190.

41. Chalasani N, Younossi Z, Lavine JE, et al. American Gastroenterological Association; American Association for the Study of Liver Diseases; American College of Gastroenterology. The diagnosis and management of nonalcoholic fatty liver disease: Practice guideline by the American Gastroenterological Association, American Association for the Study of Liver Diseases, and American College of Gastroenterology. Gastroenterology 2012;142: 1592-1609.

42. Yang FS, Yun $\mathrm{CH}, \mathrm{Wu} \mathrm{TH}$, et al. High pericardial and periaortic adipose tissue burden in pre-diabetic and diabetic subjects. BMC Cardiovasc Disord 2013;13:98.

43. Iozzo P. Myocardial, perivascular, and epicardial fat. Diabetes Care 2011;34:371-379.

44. Noyes AD, Dua K, Devadoss R, et al. Cardiac adipose tissue and its relationship to diabetes mellitus and cardiovascular disease. World J Diabetes 2014;5:868-876.

45. American Diabetes Association. Diagnosis and classification of diabetes mellitus. Diabetes Care 2010;33:62-69.

46. Ohgi K, Okamura Y, Yamamoto Y, et al. Perioperative computed tomography assessments of the pancreas predict nonalcoholic fatty liver disease after pancreaticoduodenectomy. Medicine (Baltimore) 2016;95:25-35.

47. Zeb I, Li D, Nasir K, et al. Computed tomography scans in the evaluation of fatty liver disease in a population based study: The multi-ethnic study of atherosclerosis. Acad Radiol 2012;19:811-818.

48. Smits MM, van Geenen EJ. The clinical significance of pancreatic steatosis. Nat Rev Gastroenterol Hepatol 2011; 8:169-177.

49. Gao X, Fan J-G for the Study Group of Liver and Metabolism, Chinese Society of Endocrinology. Diagnosis and management of non-alcoholic fatty liver disease and related metabolic disorders: Consensus statement from the Study Group of Liver and Metabolism, Chinese Society of Endocrinology. J Diabetes 2013;5:406-415.

50. Targher G, Day CP, Bonora E. Risk of cardiovascular disease in patients with nonalcoholic fatty liver disease. N Engl J Med 2010;363:1341-1350.
51. Cusi K. The role of adipose tissue and lipotoxicity in the pathogenesis of type 2 diabetes. Curr Diab Rep 2010;10: 306-315.

52. Iacobellis G, Corradi D, Sharma AM. Epicardial adipose tissue: Anatomic, biomolecular and clinical relationships with the heart. Nat Clin Pract Cardiovasc Med 2005;10: 536-543.

53. Liu J, Fox CS, Hickson D, et al. Pericardial adipose tissue, atherosclerosis, and cardiovascular disease risk factors: The Jackson heart study. Diabetes Care 2010;33:1635-1639.

54. Greif M, Becker A, von Ziegler F, et al. Pericardial adipose tissue determined by dual source CT is a risk factor for coronary atherosclerosis. Arterioscler Thromb Vasc Biol 2009;5:781-786.

55. Jonker JT, Lamb HJ, van der Meer RW, et al. Pioglitazone compared with metformin increases pericardial fat volume in patients with type 2 diabetes mellitus. J Clin Endocrinol Metab 2010;95:456-460.

56. Rena G, Hardie DG, Pearson ER. The mechanisms of action of metformin. Diabetologia 2017;60:1577-1585.

57. Yang J, Ren J, Song J, et al. Glucagon-like peptide 1 regulates adipogenesis in 3T3-L1 preadipocytes. Int $\mathrm{J}$ Mol Med 2013;31:1429-1435.

58. Weyer C, Bogardus C, Mott DM, et al. The natural history of insulin secretory dysfunction and insulin resistance in the pathogenesis of type 2 diabetes mellitus. J Clin Invest 1999;104:787-794.

59. van der Zij1 NJ, Goossens GH, Moors CC, et al. Ectopic fat storage in the pancreas, liver, and abdominal fat depots: Impact on beta-cell function in individuals with impaired glucose metabolism. J Clin Endocrinol Metab 2011;96: 459-467.

60. Chai J, Liu P, Jin E, et al. MRI chemical shift imaging of the fat content of the pancreas and liver of patients with type 2 diabetes mellitus. Exp Ther Med 2016;11:476-480.

61. Saisho Y, Butler AE, Meier JJ, et al. Pancreas volumes in humans from birth to age one hundred taking into account sex, obesity, and presence of type-2 diabetes. Clin Anat 2007;20:933-942.

62. Haukeland JW, Konopski Z, Eggesbo HB, et al. Metformin in patients with non-alcoholic fatty liver disease: A randomized, controlled trial. Scand J Gastroenterol 2009;44: 853-860.

63. Tock L, Damaso AR, De Piano A, et al. Long-term effects of metformin and lifestyle modification on nonalcoholic fatty liver disease obese adolescents. J Obes 2010;201:pii: 831901.

64. Li Y, Liu L, Wang B, et al. Metformin in non-alcoholic fatty liver disease: A systematic review and meta-analysis. Biomed Rep 2013;57-64.

Address correspondence to: László Czakó, $M D, D S c$ First Department of Medicine University of Szeged Korányi fasor 8-10 Szeged $H-6720$ Hungary

E-mail: czako.laszlo@med.u-szeged.hu 


\section{AUTHOR QUERY FOR MET-2018-0086-VER9-ZSORI_1P}

AU1: Please identify (highlight or circle) all authors' surnames for accurate indexing citations.

AU2: Please mention the author Eszter Pálinkás's degree abbreviations (e.g., MS, MD, PhD).

AU3: Keywords have been taken from PDF file. Please check.

AU4: Earlier Refs. 50, 56, 61, 62, and 64 were duplicates of Refs. 7, 43, 27, 26, and 31, respectively. Hence, duplicate entries have been deleted, and references renumbered. Please check.

AU5: First column headings are missing in Tables 1-3. Please check.

AU6: Please mention the significance of "bold italic" values in Tables 2 and 3. 